\title{
O DESENVOLVIMENTO DAS PESQUISAS EM FÍSICA NO BRASIL NAS DÉCADAS DE 1940 E 1950 E AS CONSEQUÊNCIAS ADVINDAS PARA O ESTUDO EM FÍSICA DE CAMPOS.
}

\author{
Pedro H. C. Vieira ${ }^{1}$; Milton Souza Ribeiro Miltão ${ }^{2}$ \\ 1. Bolsista PROBIC/UEFS, Graduando em Licenciatura em Física, Universidade Estadual de Feira de Santana \\ e-mail: vieiraphc@gmail.com, \\ 2. Orientador, Departamento de Física, Universidade Estadual de Feira de Santana, e-mail: miltaaao@gmail.com
}

PALAVRAS-CHAVE: Física Pesquisa em Física, Brasil, Física de Campos

\section{INTRODUÇÃO}

As pesquisas em Física no Brasil, do ponto de vista institucional, tiveram o inicio de sua sistematização durante a década de 1930, com a criação da Faculdade de Filosofia, Ciências e Letras da Universidade de São Paulo (FFCL/USP) em 1934 e da Faculdade Nacional de Filosofia na Universidade do Brasil (FNFi/UB) em 1939, o que possibilitou a formação de físicos capacitados ao ensino e a realizar pesquisas cientificas dentro do pais. Antes disso, aqueles que realizavam pesquisas em física no Brasil faziam de forma isolada e com recursos próprios, até mesmo para buscar formação especifica no exterior, tendo em vista que não existiam antes instituições no país com capacidade de proporcionar tal formação, tão pouco mecanismos que fornecessem bolsas de estudo dentro ou fora do país. (B ASSALO, 1990; LEITE LOPES, 2004).

Entender os processos que a partir da institucionalização levaram a consolidação das Pesquisas em Física no Brasil é essencial para que possamos refletir sobre o presente estado dessa ciência no país e traçar perspectivas para o futuro.

Assim, neste trabalho buscamos apresentar um esboço do desenvolvimento das Pesquisas em Física no Brasil nas décadas de 1940 e 1950, período no qual os primeiros grandes nomes da Física Brasileira surgem e desenvolvem suas principais pesquisas, assim como travam "grandes batalhas" pela consolidação da ciência no país, também possibilitando a fundação de grandes instituições e políticas de fomentos que proporcionaram ao país pela primeira vez políticas científicas próprias.

\section{METODOLOGIA}

Neste trabalho buscou-se compreender o processo de desenvolvimento das pesquisas em Física no Brasil nas décadas de 1940 e 1950 e quais as consequências ao estudo da Física de Campos, para isso nos utilizou-se de uma abordagem externalista da História da Ciência (MARTINS, 2005), para assim compreender quais os processos que possibilitaram a pesquisa em Física no país, sobre tudo os da institucionalização das pesquisas cientificas em Física.

A primeira etapa do projeto foi dedicada a um programa de estudo no qual se obteve o referencial teórico para uma melhor compreensão de conceitos básicos porem essenciais à Mecânica Quântica e a Mecânica Relativística, assim como os processos históricos 
que culminaram em seu desenvolvimento. Em uma segunda etapa foi dedicada ao estudo dos avanços da Física brasileira nessas áreas durante as décadas de 1940 e 1950, assim como as consequências advindas para o estudo em Física de Campos no Brasil.

\section{DISCUSSÃO}

Em São Paulo, na FFCL/USP o Departamento de Física e seus laboratórios tiveram sua organização sob a orientação do físico ítalo-ucraniano Gleb Wataghin,vindo da Universidade de Turim. Já No Rio de Janeiro, coube inicialmente ao físico alemão Bernhard Gross a responsabilidade pela organização do Departamento de física da Universidade do Distrito Federal que em 1939 foi extinta, o corpo docente e discente de tal Departamento foi integrado à FNFi da Universidade do Brasil criada no mesmo ano, cujo a organização e coordenação ficaram sob a responsabilidade de Joaquim Costa Ribeiro. (GROSS, 2000).

No fim da década de 1930 e início de 1940 formam-se, nas Faculdades de Filosofia, os alunos das primeiras turmas dos cursos de física e de matemática. Esses recém-formados físicos eram contratados para ocupar cargos de assistentes dentro dos departamentos e assim poderiam dar inicio em suas carreiras como pesquisadores, já se ocupando com temas importantes para a física na época e sendo inseridos a comunidade cientifica internacional.

A década de 1940 foi de grande trânsito internacional para os físicos brasileiros que buscavam aprimorar suas formações em grandes e tradicionais centros científicos da Europa e Estados Unidos. Ao retornarem ao Brasil ficava evidente a necessidade de mudanças e avanços quando se comparava as estruturas aqui existentes com as que haviam vivenciado no exterior.

Em São Paulo, na FFCL, iniciaram-se as construções de dois aceleradores de partículas o Betatron e o gerador Van der Graff. O Betatron foi completamente instalado em 1951, nele se aceleravam elétrons para que colidissem, dando origem a feixes de fótons para bombardear núcleos atômicos, provocando reações foto-nucleares. Três anos mais tarde, em 1954, foi instalado o gerador Van der Graff, esse gerava feixes de partículas nucleares para bombardear núcleos, afim de estudar outros aspectos da estrutura nuclear (distribuição angular dos produtos das reações, níveis de ressonância, etc.). Teve inicio a partir daí o que ficou conhecido como Era da Física Nuclear Experimental no Brasil.

No Rio de Janeiro a solução para os antigos problemas de falta de verbas destinadas a FNFi e da não concessão de regime de tempo integral aos professores entre outros, parecia ser a criação de uma instituição privada destinada a investigação cientifica. Então, em Janeiro de 1949, um grupo de físicos fundou o Centro Brasileiro de Pesquisas Física (CBPF), como uma sociedade civil sem fins lucrativos.

A criação em 1951, do Conselho Nacional de Pesquisas (CNPq), também é um marco importante, pois, proporcionou ao Brasil pela primeira vez uma política científica própria. (LEITE LOPES, 2004).

A partir de então, na década de 1950, com as melhores condições estruturais nas Faculdades de Filosofia, tanto na Universidade de São Paulo quanto na Universidade do Brasil, e também fora delas como o caso do CBPF e agora contando com professores melhor capacitados ao ensino e realizando pesquisas nos assuntos mais urgentes na física com o Brasil inserido na comunidade cientifica internacional, concessões de bolsas aos estudantes e apoio financeiro às instituições por parte da $\mathrm{CNPq}$, não só foi intensificada a circulação internacional e importância dos nossos cientificas, mas também a busca pelo aprimoramento das formações das gerações futuras. 


\section{CONSIDERAÇÕES FINAIS}

As Faculdades de Filosofia, na época, recém-criadas proporcionaram a formação dos primeiros propriamente ditos físicos brasileiros, as pesquisas que foram desenvolvidas por estes desde o principio de suas formações e continuando ao longo das décadas seguintes se mostraram de grande relevância para o cenário internacional, também foi o período de ajustes e consolidação das instituições, assim como o surgimento de algumas outras que se mostraram mais tarde importantes ferramentas a serviço do desenvolvimento cientifico brasileiro.

Os trabalhos desenvolvidos desde o inicio dos processo de Institucionalização das pesquisas em Física no Brasil, sobre os Raios Cósmicos e mais tarde, no pós-guerra, a construção de Aceleradores para o estudo da Física de Altas Energias possibilitaram no Brasil a investigação e compreensão das interações entre partículas fundamentais e os campos.

O desenvolvimento das pesquisas em física no Brasil durante as décadas de 1940 e 1950 é de valor inestimável, tendo em conta que além do desenvolvimento cientifico em investigações de fronteira na época, é impossível dissociar das lutas pela consolidação da Física no Brasil realizadas naquele período o sucesso e disseminação por todo o território nos dias atuais.

\section{REFERÊNCIAS}

BASSALO, J. M. F.; As Raízes da Física Brasileira. Ciência e Sociedade, CBPF,006/90, Rio de Janeiro, 1990.

MARTINS, L. A. P.; História da Ciência: Objetivos, Métodos e Problemas. Ciência e Educação, v. 11, n2, p.305-317, 2005.

GOLDEMBERG, J.; 100 ANOS DE FÍSICA. Ciência e Sociedade, v. 2, n2, 1973.

GROSS, B.; Lembranças de um Físico no Rio de Janeiro (1933 - 1947). Revista Brasileira de Ensino de Física, vol.22, n2, p. 266-271, 2000.

LEITE LOPES, J.. Uma História da Física no Brasil. São Paulo: Editora Livraria da Física, 2004.

SCHWARTZMAN, S.; Um Espaço Para a Ciência: a formação da comunidade científica no brasil. Ministério de Ciência e Tecnologia, Brasília, 2001.

SILVA FILHO, W.V.; Costa Ribeiro: ensino, pesquisa e desenvolvimento da Física no Brasil. Campina Grande: EDUEPB; São Paulo: Livraria da Física, 2013.

VIDEIRA, A. A. P.; "Pensando no Brasil": O Nacionalismo entre os Físicos Brasileiros no Período entre 1945 e 1955. Ciência e Sociedade, CBPF, 004/04, 2004. 